\title{
Effects of atrial fibrillation on prognosis of acute myocardial infarction
}

Sir,

In the above paper by Hunt, Sloman, and Penington (British Heart fournal, 1978, 40, 303-307) the conclusion concerning the ominous prognostic import of atrial fibrillation as an intercurrent event in acute myocardial infarction comes as no surprise but certainly needed the documentation provided here. Apparently these patients were followed for at least 12 months, since the mortality rate is recorded at 3 and 12 months. However, while the short-term duration of atrial fibrillation was carefully documented, I could find no mention of the number who maintained atrial fibrillation as a dominant rhythm on a long-term basis or what-if any-attempts at conversion were instituted. Certainly this would be additional information of great importance to the clinician. Whether patients who had more than a single episode of transient atrial fibrillation or patients who had prolonged atrial fibrillation were kept on digitalis to ensure a modest ventricular response is also not mentioned. To the same end, the use of propranolol would bear discussion.

Their conclusions in terms of prognosis are, of course, interesting. The paper by Cristal et al. (1976) points out that atrial fibrillation in their studies had no effect on the prognosis of an inferior but did affect the prognosis of an anterior wall myocardial infarction. The studies of Liberthson et al. (1976), as well as a paper by Julian et al. (1964), seem to indicate that there is no particular difference in mortality related to the presence of atrial fibrillation-which certainly is at variance with this paper. Clinical observation certainly leads me, without statistical evidence, to be prejudiced in favour of the authors.

It would have been interesting, furthermore, if the premonitory events leading to the bouts of atrial fibrillation had been further discussed. The wellknown factor of premature atrial cycles falling in the vulnerable period has been documented in the past and it might have been interesting to document this again.

\author{
Erich H. Loewy, \\ 62 Elm Street, \\ Glens Falls, N.Y. 12801, USA.
}

\section{References}

Cristal, N., Peterburg, I., and Szwarcberg (Sahar), J. (1976). Atrial fibrillation developing in the acute phase of myocardial infarction. Chest, 70, 8-11.

Julian, D. G., Valentine, P. A., and Miller, G. G. (1964). Disturbances of rate, rhythm and conduction in acute myocardial infarction. American fournal of Medicine, 37, 915-927.

Liberthson, R. R., Salisbury, K. W., Hutter, A. M., Jr., and DeSanctis, R. W. (1976). Atrial tachyarrhythmias in acute myocardial infarction. American fournal of Medicine, 60, 956-960.

This letter was shown to Dr Hunt who replies as follows:

Sir,

Of the 77 patients who lived to 3 months, 6 remained in atrial fibrillation at that time, 3 of whom were known to be in chronic atrial fibrillation before their infarction. Attempts have not been made to revert the other 3 patients to sinus rhythm, but they were still receiving digitalis. We do not have data readily available to determine how many of the patients with transient or recurrent atrial fibrillation were receiving digitalis, but would estimate that at least half would be.

We do not have full data on the timing and frequency of atrial ectopic beats and to get these data would involve reviewing all the rhythm strips by hand. Certainly atrial ectopic beats were noted in 40 per cent of the patients who had atrial fibrillation and in 20 per cent of those in whom atrial fibrillation did not develop.

David Hunt,

Department of Cardiology,

The Royal Melbourne Hospital,

Parkville,

Victoria,

Australia. 